https://doi.org/10.48009/2_iis_2005_131-139

\title{
WOULD YOU SACRIFICE YOUR JOB FOR A METHODOLOGY? A CASE STUDY IN ETHICAL AGILITY
}

\author{
Christopher G. Jones, CPA/PhD, Utah Valley State College, jonescg@uvsc.edu \\ Nate M. Jones, MCSD, N8 Werks, Inc., nate@n8werks.com
}

\begin{abstract}
Information Technology is fraught with evangelists preaching that one hardware platform, one $O / S$, one programming language or even one development methodology is the true and only path to computing salvation. In this paper, we investigate the case of a recent message submitted to a listserv by an ASIS SIGIA list subscriber that results in a forfeited job opportunity. The list subscriber had taken an ethical stance that he could not in good conscience retract his position on the appropriateness of Agile Methodologies for application development. The Software Engineering Code of Ethics and Professional Practice is examined as it relates to the case. A series of relevant ethical questions are raised that would provide a basis for classroom discussion. Finally, Agile developers who participated in a panel discussion on the topic share their individual viewpoints.
\end{abstract}

Keywords: professional ethics, code of ethics, ACM, IEEE-CS, software engineering ethics, agile methodologies

\section{INTRODUCTION}

In a recent message submitted to the listserv for the American Society for Information Science and Technology Special Interest Group for Information Architecture (ASIS SIGIA), Timothy Karsjens expressed "agilistic" angst over a job seeking incident involving a clash of methodological values.

Recently, I applied for a position with a major international company that is firmly entrenched in a strict, waterfall methodology. My posts of many moons ago on this list about embracing agile methodologies for interface architecture and development became a topic of conversation during my first, and only, telephone interview.

I did not back down on my firm belief in agile methods, across all disciplines of application development, when pressed about methodologies. The job was not worth sacrificing my ethics. I was succinctly instructed that Company A does not hire "cowboys" that believe they can work outside of the adopted process by using these unproven "agile" methods [11]. [emphasis added]

Karsjens' post raises some interesting questions:

- Given the case context, what does "sacrifice my ethics" mean?

- Would you forego a job opportunity based simply on differences between your development methodology preferences and that of your potential employer? What if you 
were already on the job using agile methodologies, when new management is brought in that imposes a waterfall approach?

- Does the desire to use a given methodological approach transcend "preference" entering the realm of "belief"?

- In Mr. Karsjens' situation, what should an Agile Methodology advocate do?

\section{THE AGILE MANIFESTO}

Dissatisfied with the current "Big Design Up Front" (BDUF) approach to software development, 17 members of what was to become the Agile Alliance met at Snowbird Village, Utah, USA on February 11, 2001 to find common ground in "uncovering better ways of developing software " [6]. Representatives from "Extreme Programming, SCRUM, DSDM [Dynamic Systems Development Method], Adaptive Software Development, Crystal, Feature-Driven Development, Pragmatic Programming, and others sympathetic to the need for an alternative to documentation driven, heavyweight software development processes" [6] spent three days forging a manifesto and a public declaration of principles. The Agile Manifesto is a value hierarchy positing one approach over another.

Figure 1. Agile Manifesto Value Hierarchy [1]

$\begin{array}{ll}\text { Individuals and interactions } & >\text { processes and tools } \\ \text { Working software } & >\text { comprehensive documentation } \\ \text { Customer collaboration } & >\text { contract negotiation } \\ \text { Responding to change } & >\text { following a plan }\end{array}$

The framers of the Agile Manifesto do not ask adherents to ignore the values on the right. Rather, they state "while there is value in the items on the right, we value the items on the left more" [1].

The manifesto is undergirded by a "rallying cry" [4] to live a set of guiding principles. Twelve principles for development practice are identified: (a) early, continuous delivery of value, (b) design for change, (c) short iteration cycles, (d) daily customer contact, (e) staffing with motivated developers, (f) efficiency and effective communication, (g) working software as a progress metric, (h) sustainable development, (i) continuous attention to design, (j) simplicity, (k) self-organizing teams, and (1) team reflection [2].

In addition to the original 17 signatories of the Agile Manifesto, the Agile Alliance website boasts hundreds of independent signatories that have elected to add their "name to the list of people signing the Agile Software Development Manifesto" [7]. Typical of these e-signers of the manifesto are Rob Lubensky of Click Craft Pty Limited and David Bock, President, Northern Virginia Java User's Group [9].

"We have a strong developer community which, as it happens, already tends to follow the ethics of this manifesto. With the growing acceptance of Agile 
philosophy, I have a better chance of successfully overcoming client conservatism and educating more to go along with the Agile approach. I am proud to sign up!" [9].

$$
\text { -- Rob Lubensky }
$$

"I have added a reference to the 'agile manifesto' to my personal mission statement, alongside the Software Engineering Code of Ethics, my company's mission statement, and the Pragmatic Programmer's 71 tips" [9].

$$
\text { -- David Bock }
$$

It would appear some Agile supporters adopt a quasi-religious stance toward software development and see themselves as "followers" of the manifesto. Karsjens" "belief in agile methods" is not an isolated instance. His post to the SIGIA listserv is a reflection of his zeal rather than a mere working preference for one methodological approach over another. He is willing to make life decisions based on a set of developer values embraced by the Agile community. In this respect, Karsjens' use of the phrase "sacrificing my ethics" becomes a synonym for "sacrificing my values". It is those "values" that enables Karsjens to make moral decisions about what is right and wrong in the workplace. However, as agilest Bock suggests, the Agile Manifesto is not the only document upon which to base one's personal ethics [9]. Another resource is the Software Engineering Code of Ethics.

\section{THE SOFTWARE ENGINEERING CODE OF ETHICS AND PROFESSIONAL PRACTICE}

In 1999, the Association of Computing Machinery (ACM) and Institute of Electrical and Electronics Engineers (IEEE) Computer Society adopted the Software Engineering Code of Ethics and Professional Practice (Version 5.2). The Software Engineering Code of Ethics (SECode) is specific to software engineers, documenting their "ethical and professional obligations." It is "intended as a standard for teaching and practicing software engineering" [5]. Both the ACM [3] and the IEEE [10] have general codes of ethics for their members, separate from the explicit code for software engineers.

The SECode encourages software engineers to adhere to eight fundamental principles. The "short version" of the code enumerates the principles using one-sentence descriptions. The "full version" provides details for each principle "to provide clear guidance for the practical application of these ethical principles" [8, p. 84]. Of particular interest to the Karsjens case are principles 2 and 3 .

Principle 2 entitled "Client and Employer" states the following:

Software engineers shall act in a manner that is in the best interests of their client and employer, consistent with the public interest [8].

A cursory reading of the overarching Client and Employer principle could lead one to cavalierly summarize Principle 2 as "the Employer/Client is always right." Fortunately, the IEEE- 
CS/ACM Joint Task Force on Software Engineering and Ethics and Professional Practice provides illustrative clauses for each general principle. On closer inspection of the Client and Employer principle in the full version of the code, $\$ 2.09$ offers "a higher authority" escape clause for practitioners that feel the Client/Employer is not always right:

Promote no interest adverse to their employer or client, unless a higher ethical concern is being compromised; in that case, inform the employer or another appropriate authority of the ethical concern [8].

For agile supporters who have incorporated the methodology into their belief system, $\$ 2.09$ stipulates a course of action when values collide. Notification is advised. Informing an "appropriate authority" may seem "over the top". After all, we are only talking about methodologies. But if an agilest can show demonstrable economic damage, possible loss of life or serious injury, or a viable threat to national security because of an inappropriate methodology selection, notification would seem reasonable.

The ethical tension between Agile methodologies and the Big Design Up Front (BDUF) heavyweight methodologies goes deep. Under Principle 3 - Product, software engineers are encouraged to "ensure that their products and related modifications meet the highest professional standards possible." Clauses $\$ 3.05$ and 3.06 specifically state:

3.05 Ensure an appropriate method is used for any project on which they work or propose to work.

3.06. Work to follow professional standards, when available, that are most appropriate for the task at hand, departing from these only when ethically or technically justified [8].

If anything, the Agile movement is about appropriate methodologies. Is it ethical to use BDUF when circumstances warrant Agile, even though BDUF is the shop standard? What if "employer loyalty" is a core value? Section 3.06 provides room for ethical justification of a less than optimal professional standard in such cases.

As the authors of the Software Engineering Code of Ethics and Professional Practice warn:

The Code is not a simple ethical algorithm that generates ethical decisions. In some situations standards may be in tension with each other or with standards from other sources. These situations require the software engineer to use ethical judgment to act in a manner which is most consistent with the spirit of the Code of Ethics and Professional Practice, given the circumstances [8].

\section{SALT LAKE AGILE SOFTWARE DEVELOPMENT PANEL}

The Utah Valley State College (UVSC) School of Computer Sciences and Engineering and the UVSC Center for the Study of Ethics sponsors a monthly discussion series entitled "Ethics in the Digital Age." The purpose of the series is to foster increased awareness of the ethical issues 
surrounding technology and to promote ethical behavior. On February 8, 2005, three members of the Salt Lake Agile Software Development Round Table (SL Agile) served as panelists in a discussion of the Karsjens case. SL Agile meets monthly to discuss software development, processes, and leadership. The three panelists were Zhon Johansen, Acadyn, Inc.; Jeff Patton, ThoughtWorks, Inc.; and Nate Jones, N8 Werks, Inc. In preparation for the panel discussion, panelists were provided a copy of the case and asked to respond to the question: What should an agile methodology advocate do given Karsjens' circumstances? Each panelist was allowed 15 minutes after which the floor was opened for a general question and answer session.

\section{Zhon Johansen}

To the question of whether it would be ethical for an agilest to accept a position in a "waterfall" shop, Zhon supplied a conditional "yes". If the company was looking to improve its software process and if he could make a difference, he would consider taking the job. Zhon believes it is wrong not to deliver what the customer wants. Further, it is morally wrong to deliver "buggy" software. Based on Zhon's experience, the BDUF approach tends to fail in both respects delivering flawed code without the features requested. Zhon is so committed to Agile Methodologies that for him "doing the right thing" could include the subversive introduction of the agile way.

\section{Nate Jones}

To introduce his response, Nate posed a rhetorical counter question: "I wonder if a waterfall advocate can say that nothing about the project will change in a typical BDUF development cycle of 18 months?" Not only is adopting a waterfall approach an act of denial, to do so is unethical. Change happens. For some organizations the best way to overcome organizational resistance to change, is to "do things under the radar." Nate commented that it is no secret that "skunk works"- -sub-organizations acting outside the process - often produce superior products. To follow a particular methodology just because it is the shop standard can be counterproductive. Of course, getting involved in "religious discussions" about a particular technology or methodology usually ends in a "lose-lose" situation. "You can't win," Nate said. The best approach is to interview the company in order to determine the underlying standards. That way the potential job candidate can better determine if there is a fit between his/her values and the organization.

\section{Jeff Patton}

For Jeff, the ethicality of Agile Methods was a new dimension he had not considered earlier. "Can I," said Jeff, "do bad work when I'm asked to and paid to?" Implicit in Jeff's question is a fundamental belief that Agilism is superior to BDUF. Jeff believes Agilism is a vehicle for achieving "QWaN — Quality Without a Name". QWan is ascribed to Christopher Alexander, the founder of the architectural patterns movement and author of "A Timeless Way of Building". Jeff advised students in the audience to introduce agilism incrementally. "Chances are you will end up working for companies with entrenched approaches that don't work," Jeff said. "As an employee, you can bring Agile to the workplace a little at a time."

\section{Student Reaction}

Students from a variety of computing disciplines attended the panel discussion In an attempt to further engage with the ethical issues raised by the Karsjens case, several students wrote reaction 
papers to the ideas presented . Responses to the question "Would you sacrifice your job for a methodology?" were mixed. A few students sided for Karsjens.

"Given the situation that the programmer was in, he was right in holding firm to his set of values regarding the way he works. The moral question is really should someone be required to work in a place in which they are not able to produce the highest quality product."

Other students were more pragmatic.

"I don't know if I would sacrifice my job for a methodology, but I think the idea of Agilism and XP are interesting and should definitely be implemented more in many businesses."

And at least one student argued that a methodology preference is a job satisfaction issue rather than an ethical decision.

"The crux of the question revolves around a belief that the client will receive a better product and the company will experience better profits by adopting the methodology. The company in question uses an inefficient software development methodology. The interviewee should recognize the company as an incompetent company and the question of whether to join the company does not involve ethics, but involves potential job satisfaction and possible viability of the company." [bold in the original]

\section{CONCLUSION}

Information Technology professionals are often passionate about hardware platforms, operating systems, programming languages, and methodologies. Apple Macintosh fanatics still regularly denounce creatively-challenged PC users. Linux advocates dream of a Windows-free world. And Java evangelists preach against evils of .NET. Zealousness is ever present in the BDUF v. Agile debate. In the Karsjens case, the telephone interviewee takes an ethical position that results in a lost job opportunity. It would seem Karsjens, an avowed Agilist, had assimilated a software methodology into his core belief system.

Agilists are troubled by software development practices destined to produce what they believe will be "buggy" products. All three agile panelists subscribe to ethical agility - the belief that agilism is the one true way. Some even go so far as to promote subversive agilism, in which light-weight methodologies are implemented "below the radar." To the question "Would you forego a job opportunity based simply on differences between your development methodology preferences and that of your potential employer?" Agile converts reply "What opportunity?" Based on comments from all three SL Agile panelists, for the serious agile practitioner, taking a job in a BDUF shop is no opportunity at all. (Unless, of course, you count the opportunity to introduce agile methodologies to the uninitiated.) No opportunity translates into nothing forgone. 
Students, on the other hand, tend to be more pragmatic. They view a methodology as nothing more than an approach, not a moral compass. Perhaps, ethical agility has little meaning for the inexperienced. "A job is a job." One can only speculate, however, but the odds are, after several years on the application development "frontline," some of these same students may grow up to be "cowboys" facing the ethical concerns of a Timothy Karsjens.

\section{REFERENCES}

1. Agile Alliance. (2001). Agile Manifesto. Retrieved January 27, 2005 from http://agilemanifesto.org

2. Agile Alliance. (2001). Principles Behind the Agile Manifesto. Retrieved March 5, 2005 from http://agilemanifesto.org/principles.html

3. Association for Computing Machinery, Inc. (1997). ACM Code of Ethics and Professional Conduct. Retreived January 24, 2005 from http://www.acm.org/constitution/code.html

4. Fowler, M. (2002). The Agile Manifesto: Where it came from and where it may go. Retrieved March 4, 2005 from http://www.martinfowler.com/articles/agileStory.html

5. Gotterbarn, D., Miller, K., \& Rogerson, S. (1999). Computer Society and ACM approve software engineering code of ethics. Computer, 32(10), 84-90. Retrieved January 24, 2005 from http://www.computer.org/computer/code-of-ethics.pdf

6. Highsmith, J. (2001). History: The Agile Manifesto. Retrieved March 2, 2005 from http://agilemanifesto.org/history.html

7. I Support the Agile Manifesto! (n.d.) Retrieved March 5, 2005 from http://agilemanifesto.org/sign/signup.cgi

8. ACM/IEEE-CS Joint Task Force on Software Engineering Ethics and Professional Practices. (1999). IEEE-CS/ACM Software Engineering Code of Ethics and Professional Practice (Version 5.2). Retrieved January 24, 2005 from http://www.acm.org/serving/se/code.htm

9. Independent Signatories of The Manifesto for Agile Software Development. (2001, October 10 - 2005, March 5). Retrieved March 5, 2005 from http://agilemanifesto.org/sign/display.cgi? ms=all

10. Institute of Electrical and Electronics Engineers, Inc. (1990). IEEE Code of Ethics. Retrieved January 27, 2005 from

http://www.ieee.org/portal/site/mainsite/menuitem.818c0c39e85ef176fb2275875bac26c8/ind ex.jsp?\&pName=corp_level1 \&path=about/whatis\&file=code.xml\&xsl=generic.xsl

11. Karsjens, T. (2004, July 15). RE: [Sigia-l] OT: Usability Prank. Message posted to Sigia1_at_asis.org, archived at http://www.info-arch.org/lists/sigia-1/0407/0158.html 